\title{
Accessibility of condoms to young people in Manchester, UK
}

\author{
Judith Sixsmith, John Griffiths, John Hughes, Joanne Wren, Steve Penfold, Hilary Natusch
}

\begin{abstract}
Background and methodology Issues relevant to the accessibility of male condoms for young people in the Greater Manchester area (UK) were investigated, using semi-structured, in-depth interviews and a questionnaire survey.

Results Family planning clinics and condom vending machines (CVMs) were the most cited sources for condom acquisition. Young people's knowledge of where and when they could access condoms varied by age and gender. Suitable positioning of CVMs would need to take such variations into account when targeting potential customers. Levels of embarrassment about acquiring condoms also varied according to gender. The lifestyles of young people indicated the sorts of places in which CVMs might offer increased accessibility. For younger men and women this tended to involve low-cost, semi-private places such as local parks, school toilets and shopping malls/streets. Older men with higher spending power and increased confidence could access condoms through pub and club toilets and chemist shops.
\end{abstract}

Conclusions Accessible positioning of CVMs was related to the age, gender and lifestyle of the participants, and programmes to enhance accessibility should reflect this. Increased accessibility for younger groups, and especially women, needs to take into account issues of cost, confidence and embarrassment. For older groups, lifestyle choices indicated pubs and clubs as key locations for both men and women.

J Fam Plann Reprod Health Care 2006; 32(4): 219-225 (Accepted 6 February 2006))

\section{Key message points}

- Male condoms were accessible to the majority of participants but knowledge and use of locations varied according to both age and gender.

- Whilst young women tended to obtain condoms from family planning clinics (FPCs), young men tended to obtain them from vending machines.

- Barriers to accessing condoms included cost embarrassment and lack of availability due to limited opening hours of shops and FPCs.

\section{Division of Psychology and Social Change, Mancheste}

Metropolitan University, Manchester, UK

Judith Sixsmith, PhD, Professor of Adult Social Care

John Griffiths, BSc, MPhil, Lecturer in Psychology

John Hughes, BSc, Research Assistant

Joanne Wren, BSc, Research Assistant

Department of Health, London, UK

Steve Penfold, MA, MIHM, Deputy Programme Manager for Sexual Health and HIV

Central Manchester Primary Healthcare Trust, Manchester, UK Hilary Natusch, MFFP, MRCGP, Consultant in Contraception and Reproductive Health Care

Correspondence to: Prof. Judith Sixsmith, Division of Psychology and Social Change, Manchester Metropolitan University, Hathersage Road, Manchester M13 0JA, UK. Tel: +44 (0) 1612472545 . E-mail: J.Sixsmith@mmu.ac.uk

\section{Introduction}

Young people's sexual health has become an important focus of attention for health authorities in the UK. Recent statistics indicate that as of 2003 , rates of pregnancy stood at 50 in every 1000 young women aged $14-19$ years in England and Wales. ${ }^{1}$ In addition, young people are at an increased risk of contracting sexually transmitted infections (STIs). ${ }^{2}$ Although the proportion of 16-19-year-olds in sexual relationships who say they always use a condom (at $68 \%$ ) is higher than for older age groups, a sizeable minority do not. Furthermore, amongst this group young women report being less likely to always use a condom than young men, in contrast to older age groups where women are more likely than men to always use a condom. ${ }^{3}$ Rates of both conceptions and STIs are influenced by the availability and accessibility of contraceptives, with barrier protection methods such as condoms being particularly important in preventing STIs. ${ }^{4}$ A number of studies have suggested that factors restricting access to contraceptive services for young people (such as limited provision outside school hours) exist, and that accessibility should be improved. ${ }^{5,6}$ Services that are available to young people through weekday lunchtimes, evenings and weekends, for instance, would improve the accessibility of condoms to young people. ${ }^{7}$ One possible strategy for improving access to condoms outside current family planning clinic (FPC) opening times is to increase access to condom vending machines (CVMs) for young people.

Young people in particular may be concerned about embarrassment and confidentiality in accessing contraceptives, ${ }^{8}$ and so prefer to obtain condoms from locations where confidentiality is assured and public visibility is low. If more private locations are not available to young people then the accessibility of condoms is likely to be limited. ${ }^{9}$ Moreover, access to proprietary condoms for young people with relatively little disposable income is also likely to be limited by their cost. The empirically observed association between socioeconomic deprivation, STIs $^{10}$ and pregnancy ${ }^{11}$ amongst young people has led to the introduction of social marketing programmes in some lower income countries 12 in an attempt to make condoms available at a price that will be affordable to those young people who are economically disadvantaged.

Relatively little is known about the current pattern of young people's condom acquisition in the UK. A survey of 16-19-year-olds in South Thames, London, UK ${ }^{13}$ found that chemists were the most frequently used places for obtaining condoms, ahead of vending machines. It was found that a much higher proportion of young men used CVMs than young women. Conversely, a much higher proportion of young women used FPCs to obtain condoms than young men. However, both men and women identified CVMs as being the point of access they would feel most comfortable using. This raises the question of why a higher proportion of young women did not report actually using CVMs to obtain condoms. It may be that young women found CVMs to be less accessible than did young men, or that the cost of condoms from CVMs was restrictive in comparison with their availability without charge at FPCs.

Currently, young people's perceptions about the accessibility and availability of condoms are underresearched. One study in London ${ }^{14}$ found that whilst 
ARTICLE

Table 1 Stratification of the study population

\begin{tabular}{|c|c|c|c|c|c|}
\hline Study population $(n)$ & $\begin{array}{l}\text { Area 1: } \\
\text { East Manchester }\end{array}$ & $\begin{array}{l}\text { Area 2: } \\
\text { Wythenshawe }\end{array}$ & $\begin{array}{l}\text { Area 3: } \\
\text { Hulme and Moss Side }\end{array}$ & $\begin{array}{l}\text { Area 4: } \\
\text { North Manchester }\end{array}$ & Total \\
\hline \multicolumn{6}{|l|}{ Males } \\
\hline 14-16 years & 10 & 10 & 10 & 10 & 40 \\
\hline $17-19$ years & 10 & 10 & 10 & 10 & 40 \\
\hline \multicolumn{6}{|l|}{ Females } \\
\hline 14-16 years & 5 & 5 & 5 & 5 & 20 \\
\hline $17-19$ years & 5 & 5 & 5 & 5 & 20 \\
\hline Total & 30 & 30 & 30 & 30 & 120 \\
\hline
\end{tabular}

around half $(51 \%)$ of 16-17-year-olds reported being aware of the availability of condoms from chemists, only $11 \%$ were aware they could be obtained from FPCs. Just less than one-third reported an awareness that condoms could be obtained from toilets and less than one-fifth from pubs.

The limited research that has looked at issues around condom accessibility for young people has identified lack of knowledge, availability, embarrassment and cost as potential barriers. How such issues vary in their importance according to gender and age is currently not fully known. There is a need for further research that helps to develop a richer understanding of the complex nature of these issues from the perspective of young people themselves.

The present study addressed the following research questions with particular attention to differences in the age and gender of the young people concerned:

- What knowledge do young people have regarding the availability of male condoms?

- Where do young people obtain male condoms?

- What are the barriers to obtaining male condoms as perceived by young people?

- How might accessibility of male condoms be increased?

\section{Methods}

Semi-structured interview and questionnaire survey methods were used to address the above research questions. This was a 6-month exploration of a condom vending service funded by Central Manchester Primary Care Trust and conducted in accordance with the British Psychological Society ethical guidelines. ${ }^{15,16}$ In this respect, issues of informed consent, briefing, protection from harm, anonymity, withdrawal from the study and debriefing were all taken into account. Participants were aged between 14 and 19 years old and lived in and around the Greater Manchester area. The sampling framework was opportunistic, whereby young people were randomly selected within the following locations: youth clubs, parks, residential streets, school districts, nightclubs/pubs and shopping centres. Youth workers facilitated access to those young people who took part in questionnaire surveys within youth clubs. The gender/age profile reflected the proposed target group for a proposed CVM service. The proportion of males to females in the sample was 2:1, reflecting the plans for the service of around $40 \mathrm{CVMs}$ being accessible to males and around $20 \mathrm{CVMs}$ being accessible to females.

Four of the young men and two young women agreed to take part in semi-structured interviews. An interview schedule was constructed allowing participants to voice their own thoughts and feelings about contraception, condoms and accessibility issues. The interviews took place in the homes of the participants and lasted between 45 minutes and 1 hour. They were taped, transcribed and analysed using a thematic analysis framework (e.g. Boyatzis ${ }^{17}$ ). In the following results section, quotations from transcriptions were selected on the basis of relevance to the study aims and research question under analysis. In all cases, pseudonyms are used to preserve the anonymity of participants.

For the survey study, a draft questionnaire was constructed based on a review of the literature, information from the in-depth interviews and consideration of the aims of the study. This was piloted with 12 young people, giving rise to a final questionnaire containing 44 unprompted questions in which the following topics were addressed: attitudes towards contraception, contraception and sexual behaviour, accessing condoms, and possible locations for CVMs. A total of 120 participants were recruited (as detailed above) for the survey from four geographical areas of Greater Manchester with relatively high levels of socioeconomic deprivation: East Manchester (Beswick, Clayton, Bradford, Gorton, Openshaw); Wythenshawe; Hulme and Moss Side; and North Manchester (Cheetham Hill, Blackley, Moston). Street interviews were carried out primarily in weekday and weekend afternoons and early evenings. The sample size was chosen to reflect the limited time allotted for completion of the study prior to CVMs actually being placed. This constituted a stratified purposive sample configured as in Table 1 .

The geographical areas chosen reflected those areas in which CVMs were going to be placed as part of the project, and the key geographical information being sought was suggestions from participants for actual locations in which to place machines. For the purpose of this paper we have collated these suggestions into generic categories (e.g. parks). Questionnaires were conducted in face-to-face street interviews lasting approximately 15-20 minutes each. Two male interviewers and one female interviewer (all aged between 22 and 30 years) and living locally were engaged to collect the data (sex matched to participants).

\section{Results}

The interviews and questionnaires yielded data concerning: knowledge of condom availability, locations from which young people obtain condoms, barriers to accessing condoms, and improving condom accessibility. Interviews and qualitative questionnaire responses were thematically analysed and closed-question survey responses subjected to statistical analysis. Attention to similarities and differences between males and females as well as younger (14-16year-olds) and older (17-19-year-olds) groups are made in this analysis. Key themes are presented below, bringing together both qualitative and quantitative information.

\section{Knowledge of condom availability}

Participants were asked in both interviews and questionnaire format about their current knowledge of locations from which condoms were available. In questionnaire responses to the open-ended question "What places can you get condoms from, including specific locations?", the most frequently cited locations were chemists (42\% of participants), FPCs (including Brook Advisory Centres) (30\%) and pub toilets (20\%). Responses were tabulated based on frequency of citation and are shown in Table 2. 
Table 2 Locations from which condoms are perceived to be available

\begin{tabular}{llllll}
\hline Location & \multicolumn{4}{l}{ Study population $(n)$} & \\
\cline { 2 - 6 } & $\begin{array}{l}\text { Males } \\
(14-16\end{array}$ & $\begin{array}{l}\text { Females } \\
(14-16\end{array}$ & $\begin{array}{l}\text { Males } \\
(17-19 \\
\text { years })\end{array}$ & $\begin{array}{l}\text { Females } \\
(17-19 \\
\text { years })\end{array}$ & Total \\
\hline Chemists & 14 & 11 & 17 & 8 & 50 \\
FPCs & 6 & 6 & 9 & 15 & 36 \\
Pub toilets & 11 & 1 & 12 & 0 & 24 \\
Youth clubs & 15 & 1 & 0 & 2 & 18 \\
Local shops & 5 & 2 & 7 & 2 & 16 \\
Doctors & 5 & 2 & 0 & 6 & 13 \\
Public toilets & 1 & 1 & 2 & 2 & 6 \\
\hline
\end{tabular}

FPC, family planning clinic.

Age differences were observable in that a higher proportion of younger participants than older participants reported that condoms were available in youth clubs [Chisquare value $\left(\chi^{2}\right)=11.04$, degrees of freedom $(\mathrm{df})=1$, significance level $(\alpha)=0.01]$. Also a higher proportion of the older group reported that condoms were available from FPCs $\left(\chi^{2}=4.8, \mathrm{df}=1, \alpha=0.05\right)$. In addition, clear gender differences were seen whereby women were much less likely to cite pub toilets as the location for available condoms than men $\left(\chi^{2}=16.92, \mathrm{df}=1, \alpha=0.01\right)$ but much more likely to cite FPCs than men $\left(\chi^{2}=12.9\right.$, df $=1, \alpha=$ $0.01)$.

The interview data further elucidated age and gender issues. In the following extract from an interview with a 19-year-old woman, Susan reported that the majority of people her age would be aware of locations from which condoms may be accessed.

Interviewer: Do you know where you can get condoms from? Erm, do you think most people your age would probably know where they can get them from?

Susan: $\quad Y e a h$, erm, I think yes, the majority of them. Some of them probably, but I mean, I always think family planning clinics and stuff, people aren't always aware that "Oh yeah, you can go and there's a lot of them that you can get free", and things like that, and they're not always aware, and I know that's something. But I think the majority of people do tend to know.

Susan was aware of the availability of free condoms from FPCs, but drew attention to this as an issue that not all people of her age are clear about. In raising this point she also drew attention to the issue of the cost of proprietary condoms, likely to be important to young people with relatively little disposable income (see section on 'Barriers to accessing condoms'). Her perception that the majority of her peers are knowledgeable about condom availability can be contrasted with the uncertainty evident in the following extract from an interview with a 14-year-old male.

Interviewer: So are you aware of what kinds of places you could get condoms from?

Colin: $\quad$ Not really, er, I mean some friends will have them but I don't really, so, I don't know.

Interviewer: Where do you think your friends would get them?

Colin: I I suppose toilets, I mean I've seen condoms and I know what they're for but I haven't got a girlfriend so I don't need them.

Interviewer: Would most of your friends know where they could get them?

Colin: Dunno. I mean you just think toilets sometimes. Er. Don't have them in school toilets though.

Whilst Colin reported that condoms might be available in toilets, his initial response indicated that he was unsure of the variety of locations from which they may be obtained. He reported that whilst some of his peers are able to obtain condoms, he was uncertain where they have been obtained. As a 14-year-old without a girlfriend, the availability of condoms was not really an issue relevant to him. In terms of placement of CVMs, Colin's age meant that pub or club toilets were inaccessible to him and those in school did not contain CVMs, making access to condoms difficult.

\section{Locations from which to obtain condoms}

Aside from knowledge of availability, survey participants were also asked if they had ever actually acquired condoms. The majority of the sample $(78 \%)$ stated that they had. A higher proportion of males than females $\left(\chi^{2}=\right.$ 10.32 , $\mathrm{df}=1, \alpha=0.01)$, and of the older group than the younger group $\left(\chi^{2}=5.94\right.$, df $\left.=1, \alpha=0.05\right)$, answered positively to this question. Those participants who had previously obtained condoms were asked to state where they had ever obtained condoms, giving a measure of accessibility linked to relevance. In the questionnaire survey they stated in answer to the question "Which of the following places have you ever got condoms from?" whether they had ever obtained condoms from chemists, supermarkets, petrol stations, FPCs, CVMs or 'other places'. The results can be seen in Table 3. The most cited location was the FPC ( $47 \%$ of those who had ever obtained condoms), closely followed by a CVM (38\% of those who had ever obtained condoms).

Where participants responded that they had obtained condoms from 'other places' they were asked to describe these via an open response box on the questionnaire. Of those who filled in this box, family and friends $(n=18)$, youth clubs $(n=10)$ and local shops $(n=1)$ were

Table 3 Locations from which young people had ever got condoms

\begin{tabular}{|c|c|c|c|c|c|c|c|c|c|c|c|c|}
\hline \multirow{3}{*}{$\begin{array}{l}\text { Study } \\
\text { population }\end{array}$} & \multicolumn{12}{|c|}{ Location for obtaining condoms $[n(\%)]$} \\
\hline & \multicolumn{2}{|l|}{ Chemist } & \multicolumn{2}{|c|}{ Supermarket } & \multicolumn{2}{|c|}{ Petrol station } & \multicolumn{2}{|c|}{ Vending machine } & \multicolumn{2}{|c|}{ FPC and Brook } & \multicolumn{2}{|c|}{ Other place } \\
\hline & Ever & Regularly & Ever & Regularly & Ever & Regularly & Ever & Regularly & Ever & Regularly & Ever & Regularly \\
\hline Males & $22(31)$ & $12(17)$ & $7(10)$ & $5(7)$ & $13(19)$ & $8(11)$ & $33(47)$ & $26(37)$ & $22(31)$ & $18(26)$ & $23(33)$ & $19(27)$ \\
\hline Females & $6(25)$ & $5(21)$ & $2(8)$ & $0(0)$ & $1(4)$ & $0(0)$ & $3(13)$ & $0(0)$ & $22(92)$ & $19(79)$ & $2(8)$ & $2(8)$ \\
\hline $\begin{array}{l}14-16 \text { years } \\
\text { age group }\end{array}$ & $11(27)$ & $4(10)$ & $5(12)$ & $3(7)$ & $4(10)$ & $3(7)$ & $15(37)$ & $11(27)$ & $17(42)$ & $13(32)$ & $19(46)$ & $16(39)$ \\
\hline $\begin{array}{l}17-19 \text { years } \\
\text { age group }\end{array}$ & $17(32)$ & $13(25)$ & $4(8)$ & $2(4)$ & $10(19)$ & $5(9)$ & $21(40)$ & $15(28)$ & $27(51)$ & $24(45)$ & $6(11)$ & $5(9)$ \\
\hline Total & 28 & 17 & 9 & 5 & 14 & 8 & 36 & 26 & 44 & 37 & 25 & 21 \\
\hline
\end{tabular}

The results are given as a frequency and as a percentage (values in parentheses) of those who had ever obtained condoms before. FPC, family planning clinic. 


\section{ARTICLE}

mentioned. Participants were similarly asked which locations they regularly used when accessing condoms, in order to gain an understanding of the most popular locations. Here, the FPC (31\% overall) and CVM (22\% overall) were again the most cited locations (Table 3 ).

Gender differences were apparent in the locations from which the sample reported obtaining condoms. Women were more likely to have 'ever used' an FPC $\left(\chi^{2}=7.5\right.$, df $=$ $1, \alpha=0.01$ ) or to 'regularly use' an FPC as a place to get condoms $\left(\chi^{2}=6.69\right.$, df $\left.=1, \alpha=0.01\right)$. Conversely, men were more likely to have 'ever used' a CVM than were women $\left(\chi^{2}=12.9\right.$, $\left.\mathrm{df}=1, \alpha=0.01\right)$. Men were also more likely to have ever obtained condoms from 'other' sources $\left(\chi^{2}=7.74, \mathrm{df}=1, \alpha=0.01\right)$ or to regularly obtain them from 'other' sources $\left(\chi^{2}=5.26, \mathrm{df}=1, \alpha=0.05\right)$. Even more striking was the finding that no women and a significantly high proportion of men reported using a CVM regularly to obtain condoms $\left(\chi^{2}=14.74, \mathrm{df}=1, \alpha=0.01\right)$. One reason for this may be the higher proportion of women who obtain condoms free from FPCs therefore not needing to use CVMs (another possible explanation for this is explored below in the section on 'Barriers to accessing condoms').

The older age group were more likely than the younger age group to regularly obtain condoms from a chemist $\left(\chi^{2}\right.$ $=4.39, \mathrm{df}=1, \alpha=0.05)$ or an FPC $\left(\chi^{2}=3.91, \mathrm{df}=1, \alpha=\right.$ $0.05)$. The younger age group were more likely to ever obtain condoms from 'other' places $\left(\chi^{2}=7.28, \mathrm{df}=1, \alpha=\right.$ $0.01)$ and to regularly obtain them from 'other' places $\left(\chi^{2}\right.$ $=5.77, \mathrm{df}=1, \alpha=0.05$ ).

The qualitative material supported and elaborated the notion of gender differences in patterns of obtaining condoms and was useful in suggesting possible reasons for these. The following extract comes from an interview with Dan, a 16-year-old man.

Interviewer: Do you know whereabouts in this area you can get condoms?

Dan: $\quad$ There's a place in Manchester centre called Brook, where girls go, for the pill and condoms.

Interviewer: Right, have you ever gone there?

Dan: No.

Interviewer: No. Have you ever bought condoms, got condoms?

Dan: Yeah.

Interviewer: Where do you get them from?

Dan: Usually pub toilets.

Interviewer: Pub toilets, right. Is there any particular reason you prefer to get them from pub toilets?

Dan: It's more private, it's a bit embarrassing really.

Noticeable in this extract is the way in which Dan perceived the Brook Advisory Centre as a feminised space ("where girls go"). Whilst such centres do not restrict their facilities according to sex, social conventions may ensure that men are self-excluded, making access to free condoms difficult for young men with little disposable income. Dan was typical of the high proportion of men who reported regularly obtaining and thereby paying for condoms from CVMs. He cited the anonymity with which this can be achieved and the consequent reduction in potential for embarrassment as an explanation. Through obtaining condoms in pub toilets the number of people who are likely to observe his actions could be controlled and limited. It may also be important that since pub toilets are generally sex-segregated, women were excluded altogether from observing him engaging in, what was for him, a highly private activity.
Table 4 Barriers to accessing condoms (agreements ${ }^{a}$ )

\begin{tabular}{llllll}
\hline $\begin{array}{l}\text { Barrier to } \\
\text { accessing } \\
\text { condoms }\end{array}$ & \multicolumn{4}{l}{ Study population $[n(\%)]$} & \\
\cline { 2 - 6 } & Males & Females & $\begin{array}{l}14-16 \\
\text { years age } \\
\text { group }\end{array}$ & $\begin{array}{l}17-19 \\
\text { years age } \\
\text { group }\end{array}$ & Total \\
\hline $\begin{array}{l}\text { Buying condoms } \\
\text { in shops is } \\
\text { embarrassing }\end{array}$ & $41(52)$ & $31(78)$ & $38(63)$ & $34(54)$ & $72(60)$ \\
$\begin{array}{l}\text { Condoms are too } \\
\text { expensive }\end{array}$ & $19(24)$ & $18(45)$ & $16(27)$ & $21(35)$ & $37(31)$ \\
$\begin{array}{l}\text { There is nowhere } \\
\text { locally to get } \\
\text { condoms }\end{array}$ & $15(19)$ & $10(26)$ & $15(25)$ & $10(17)$ & $25(21)$ \\
$\begin{array}{l}\text { Using the FPC to } \\
\text { get condoms is } \\
\text { embarrassing }\end{array}$ & $34(43)$ & $10(25)$ & $26(43)$ & $18(31)$ & $44(37)$ \\
\hline
\end{tabular}

The results are given as a frequency and as a percentage (values in parentheses) of the sample.

aThe frequency of agreements was derived by combining responses to 'agree' and 'strongly agree' on the Likert scale.

FPC, family planning clinic.

\section{Barriers to accessing condoms}

The interviews and questionnaire survey both produced evidence of a number of barriers to accessing condoms. Initially, survey participants were asked to rate "How easy or difficult is it for you to get hold of condoms?". Whilst the majority $(56 \%)$ responded that it was easy, just under one-third (28\%) reported that it was 'sometimes a problem' and $4 \%$ that it was 'difficult' for them to get hold of condoms ( $12 \%$ said the question didn't apply to them). The participants were also asked to indicate their level of agreement with statements concerning potential barriers to accessibility using a five-point agree to disagree Likert scale (Table 4)

The results shown in Table 4 can be interpreted to represent three distinct barriers to accessibility: lack of availability, embarrassment and expense. These are discussed below.

Lack of availability and accessibility. While the majority of survey participants disagreed (in total $69 \%$ responded with disagree or strongly disagree) with the statement that there are no places locally to get condoms, a large minority $(21 \%)$ agreed or strongly agreed that there was nowhere locally for them to get condoms. Of particular relevance to the accessibility of CVMs to women were the responses to an open-response question asking participants to state the reasons why they found it difficult to access condoms. A relatively high proportion (five women, $45 \%$ ) of those who had stated that they found such a difficulty (11 women) cited a lack of CVMs placed in female toilets (pub and nightclub toilets were those specifically indicated). This may be reflected in the finding that women rarely reported using CVMs as a main source of condoms.

Lack of accessibility also appeared as a barrier during the in-depth interviews whereby young people mentioned that shops and FPCs were closed when they were needed or were prohibitively distant. This was linked to the need for condoms in spontaneous situations, especially when friends were not able to supply them. The following extract from an interview with a 19-year-old woman suggested a lack of provision of CVMs in locations that fit in with the lifestyles of young women.

Interviewer: Do people around your age carry condoms just in case? I mean do you think people...

Susan: I I think some people would, I think some, I 
ARTICLE

Table 5 Respondents who agreed that the right price would encourage purchase of condoms

\begin{tabular}{|c|c|c|c|c|c|}
\hline \multirow[t]{2}{*}{ Circumstance } & \multicolumn{5}{|c|}{ Study population $[n(\%)]$} \\
\hline & Males & Females & $14-16$ years age group & $17-19$ years age group & Total \\
\hline In case of unplanned sexual act & $47(59)$ & $20(50)$ & $32(53)$ & $35(58)$ & $67(56)$ \\
\hline For planned sexual act & $26(33)$ & $10(25)$ & $20(33)$ & $16(27)$ & $36(30)$ \\
\hline Not sure & $7(9)$ & $10(25)$ & $8(13)$ & $9(15)$ & 17 (14) \\
\hline
\end{tabular}

The results are given as a frequency and as a percentage (values in parentheses) of the sample.

mean, I've got a couple, well, one friend in particular who's very kind of, not promiscuous but does kind of like go out and always like, like always thinks like "you never know", so don't kind of, just in case, 'cos also there's the thing of, if you go in [pubs] and they don't have them or it's like, even in toilets and stuff, it's only in male toilets in certain places, so she does it just to make sure.

Susan related the necessity of carrying condoms 'just in case' to a lack of availability of condoms in female toilets. Overcoming this barrier required forward planning. Young women who have not equipped themselves with condoms prior to 'going out' might be dependent for their access to condoms on men, thereby losing control over their own decision making.

Embarrassment. Throughout the survey, participants referred to embarrassment as a barrier to accessing condoms. Some $60 \%$ of all participants (i.e. including participants who had never acquired condoms) agreed or strongly agreed that "Buying condoms from shops is embarrassing". Women were much more likely to agree (or strongly agree) than men that buying condoms in shops is embarrassing $\left(\chi^{2}=6.60\right.$, df $\left.=1, \alpha=0.05\right)$. For all groups, FPCs were perceived as being less embarrassing to obtain condoms from than shops $(37 \%$ compared to $50 \%$, respectively). Nevertheless, $37 \%$ is a sizable minority of the sample, and clearly visiting the FPC can be perceived as an embarrassing experience for many young people.

The in-depth interviews indicated that embarrassment in accessing condoms arose where social interaction was necessary, as illustrated in the following two interview extracts with a 17-year-old man and 15-year-old woman.

Interviewer: Would you ever go to a chemist or a supermarket to get condoms?

Karl: $\quad$ No. No. If I go to a chemist or a supermarket ...I'm scared of them asking for a price check or something ... it's a bit embarrassing really.

Interviewer: So you reckon that a lot of people in this area would know where to get free condoms from?

Jodie: Yeah, yeah, you get up to thirty at a time [from the FPC] as well, so, that's a lot. I don't know, I don't think many people'd use a machine round here. Well, I don't know 'cos some people are embarrassed about goin' the clinic, especially younger people when the older people are there, 'cos I know I have been ... and I like to go with someone who's older rather than goin' in with me mates.

For Karl the unpredictability of the social aspect involved in obtaining condoms from chemists or supermarkets led him to fear public awareness of his interest in sexual activity. Consequently he was reluctant to use such outlets. Embarrassment also appeared as a barrier in Jodie's account. Jodie circumvented embarrassment by enlisting the help of a known and sympathetic older person. It may be that as a 15-year-old and below the legal age for consent to sexual behaviour she felt she would be less likely to be challenged. In both these cases the potential disapproval of adults towards young peoples' sexual activity introduced barriers to accessing condoms, which the young people strove to overcome.

Expense. Women were also more likely to perceive condoms as expensive, with $45 \%$ agreeing with the statement "Condoms are too expensive" compared to just $24 \%$ of men $\left(\chi^{2}=4.69\right.$, df $\left.=1, \alpha=0.05\right)$. Regarding affordable pricing, all groups stated that a three-pack for $£ 1$ was 'about right' (men, $84 \%$; women, $78 \%$; younger, $80 \%$; older, $83 \%)$. A few people felt that $£ 1$ was too cheap $(6 \%$, $10 \%, 8 \%$ and $7 \%$, respectively). This is important since the sample felt that the right price would encourage them to buy a pack, especially as a precaution (Table 5). Interestingly, at this level of abstraction concerning questioning about potential future behaviour, a degree of uncertainly is evident in the 'don't know' answers (especially for women).

Cost as a barrier also appeared in the interview with Jodie, whereby the availability of free condoms from the local FPC was perceived as a disincentive for people to pay for them using CVMs. For some young people with little disposable income, then, there are likely to be tensions between the embarrassment associated with obtaining free condoms from an FPC and the cost associated with obtaining condoms more anonymously from CVMs. This illustrates some of the complexity involved around issues of expense and the sources from which condoms were obtained.

\section{Improving condom accessibility}

Finally, both the questionnaire survey and interviews were used to elicit young people's own ideas about ways in which condom accessibility might be improved. In the questionnaire survey, young people were asked in an openended way to suggest three (specific) places where they would be comfortable buying condoms from a vending machine, and a further two specific places where CVMs could be placed should the other places be inaccessible to them. By far the most frequently cited locations were toilets (pub, public, school/college, cinema or youth club) amongst both men and women. Other places mentioned included parks and outside shops.

In the following interview extract, Susan (a 19-year-old woman) suggests that gender barriers to accessibility should be remedied by the placement of CVMs in female toilets.

Interviewer: Erm, right, if there was an ideal place where you could go and buy a condom, what would it be?

Susan: $\quad M m m$... It's just when you feel comfortable, so, whether it's, if you don't like going in chemists or like, big places like Boots because you feel embarrassed, then, you 
know, it's being able to go into like a female toilet and get them there, 'cos not, and not all female toilets have them in, it's mostly male ones. So it's being able to, you know, find a balance, if you don't like one place.

Susan identified both embarrassment and comfort in use as being key issues to enhance accessibility and suggested that CVMs in female toilets would empower more women with respect to their sexual activity.

Moreover, lifestyle issues were predominant in the indepth interviews. Keith (a 14-year-old) suggested that placing CVMs in locations where young people congregate would improve accessibility.

Interviewer: Where would you think machines selling condoms should go then?

Keith: $\quad$ Toilets I suppose. Just more toilets.

Interviewer: OK. Any places other than toilets? That'd be convenient for you and your friends?

Keith: Er. Don't know really. Erm. Maybe at the Metrolink [tram] station. In Spice Shack [takeway food outlet] on the main road.

It is interesting to note that Keith's first suggestion follows a pattern seen in responses to the questionnaire survey whereby young people tended to suggest the kinds of places where one would already expect to find condom machines (e.g. toilets). Upon being pressed, however, and when the question was framed in terms of convenience, Keith was able to propose more imaginative locations. These were convenient in terms of Keith's lifestyle, as well as being places without age restrictions. Thus it is important to know something about where young people spend their time in order to place CVMs conveniently for them. School and work apart, we therefore asked two questions in the questionnaire survey about where participants spent their free time: "Where do you go on weekday evenings?" and "Where do you go at the weekends?". Responses to these two social life questions were combined and are presented in Table 6.

The younger sample (14-16-year-olds) tended to spend a lot of their evening leisure time in places with little or no financial implications. These places included hanging around on local streets, youth clubs, local parks, friends and partners' houses, pubs (predominantly among women and restricted to weekends), nightclubs and 'raves' (again predominantly among women and restricted to weekends) and the town centre. In contrast, the older sample (17-19year-olds) tended to spend their evening leisure time in places that reflected their increased spending power and accessibility of locations imposing age restrictions. Thus the older sample reported that they spent their evening leisure time in pubs and nightclubs. Other places identified included family and friends' houses, the cinema and local parks.

Table 6 Social life of study participants

\begin{tabular}{llllll}
\hline $\begin{array}{l}\text { Location where } \\
\text { free time spent }\end{array}$ & \multicolumn{5}{l}{ Study population $(n)$} \\
\cline { 2 - 6 } & $\begin{array}{l}\text { Males } \\
(14-16\end{array}$ & $\begin{array}{l}\text { Females } \\
(14-16\end{array}$ & $\begin{array}{l}\text { Males } \\
(17-19 \\
\text { years })\end{array}$ & $\begin{array}{l}\text { Females } \\
(17-19 \\
\text { years })\end{array}$ & Total \\
years $)$ & \\
\hline Local streets & 26 & 15 & 0 & 8 & 49 \\
Local parks & 10 & 8 & 6 & 2 & 26 \\
Youth clubs & 17 & 4 & 1 & 3 & 25 \\
Friends/family houses & 7 & 6 & 10 & 10 & 33 \\
Pubs & 4 & 10 & 36 & 16 & 66 \\
Nightclubs and raves & 2 & 5 & 20 & 9 & 36 \\
Cinema & 3 & 1 & 9 & 4 & 17 \\
Town centre & 5 & 5 & 1 & 0 & 11 \\
\hline
\end{tabular}

\section{Discussion and conclusions}

Our study was limited to a relatively small sample size, in particular with regard to young women, and the results of the questionnaire survey may be regarded as tentative in this respect. Many of the young people who took part were surveyed outdoors in locations such as youth clubs, parks, pubs, and so on, meaning that the thoughts of those who spend their leisure time in their own or others' homes are less likely to be represented here. Given such limitations, we found the combined use of a qualitative interview and quantitative survey approach to be helpful in a number of ways. The qualitative material was initially useful in formulating relevant questions for the questionnaire survey. The rich depth of information highlighted important meanings as well as pointing to age- and genderrelated explanations of survey findings. Further larger-scale quantitative and qualitative research might productively explore these issues further.

Although only $32 \%$ of participants stated that they had some difficulty in obtaining condoms, this is an unacceptably large minority in the light of the levels of teenage conception and risk of contracting STIs that have been described.1,2 The majority of young people interviewed and surveyed were aware of at least one type of place from which condoms could be obtained. Differences in knowledge of the variety of places providing condoms according to both age and gender were apparent however. A much higher proportion of men cited pub toilets, for instance, whilst a much higher proportion of women cited FPCs. In previous research ${ }^{14}$ age differences in knowledge about where condoms may be obtained have been observed (between 12-13-year-olds and 16-17-yearolds) but gender differences amongst young people of similar age have not generally been remarked upon. Gender differences in knowledge of locations from which condoms may be obtained were mirrored in terms of locations from which condoms were actually obtained.

Regarding age differences in knowledge, the qualitative material was useful in highlighting motivational differences between older and younger groups. In contrast to older participants, the younger participants were less likely to be in a sexual relationship and therefore not so concerned about obtaining condoms. The uncertainty and limited knowledge that was apparent in qualitative responses from younger participants may have partly reflected this. The varying age-related lifestyles (e.g. school-based or nightclub-oriented) should also be considered in relation to condom awareness and accessibility, and such knowledge used to situate condoms in more accessible locations.

The cost of proprietary condoms was a barrier to many of the young men and women who were surveyed. Many suggested that condoms were too expensive, with women $(45 \%)$ being more likely to agree that proprietary condoms were too expensive than men (24\%). Whilst the majority of young people surveyed were aware of locations from which they could access free condoms, only a minority of those who had ever obtained condoms reported that they regularly obtained them (for free) from FPCs. This finding was related to the lower proportion of young women in our sample compared to young men, since the vast majority of young women who had ever obtained condoms reported that they regularly obtained them from FPCs. The comparative financial aspects may be implicated in our finding that no women regularly used CVMs to obtain condoms. Qualitative data indicated a possible contributing factor to men's much lower regular use of FPCs, namely that FPCs may be seen by a proportion of men as a feminised space, and as a consequence they may be 
uncomfortable about using them. Further research would be useful to investigate further young men's perceptions of FPCs, influences upon these, and the ways in which they affect patterns of condom acquisition. Perhaps the terminology relating to 'family planning' is off-putting to young men whose interest may lie less in 'families' and more in 'sex'. Furthermore, there is a need for large-scale surveys into the placement, availability and quality of male condoms distributed via CVMs in comparison with other outlets for accessing condoms.

Since a quarter $(25 \%)$ of the women agreed that using the FPC to obtain condoms is embarrassing, one would have expected some proportion of the female sample to have been regularly using CVMs. Indeed, previous UK research ${ }^{13}$ has suggested that young women would feel most comfortable accessing condoms from CVMs. However, CVMs are less available to women than men, being placed more often in men's than in women's toilets, and there is a lack of choice for women in regard to locations where CVMs may be accessed. Both men and women stated in the survey that CVMs should be located in accessible yet private places such as toilets. Future research could usefully investigate empirically the distribution of CVMs in locations accessible to young women such as female toilets, in comparison to those accessible to young men.

One conclusion following from the gender pattern of condom acquisition is that the opening times of FPCs and chemists are perceived as a barrier to accessing condoms for women in particular. A number of the older women in the survey stated that FPC opening times, shop opening times and embarrassment about buying condoms from a shop when the FPC was closed were barriers to accessing condoms. This is problematic in that substantial personal planning is required to obtain condoms in advance from FPCs, whereas young women's lifestyles often involved socialising in pubs and nightclubs and spontaneous, unplanned sexual encounters occur. Young women's control over the use of condoms may be enhanced should their accessibility in such places be improved.

The finding that many young people felt embarrassed about obtaining condoms in interpersonal and visible situations concurs with the findings of other studies. ${ }^{15}$ However, gender differences were apparent in the degree to which embarrassment was a barrier to accessibility (e.g. more women than men felt embarrassed to get condoms in shops). Further research would be useful to better understand the reasons for the differential perception of place-based embarrassment as well as how gender constructions and current (disapproving) norms on young people's sexual behaviour may be implicated in this

We sought young peoples' own suggestions as to where CVMs should be placed to maximise their accessibility. These seemed to reflect locations already used for CVMs, with pub toilets being the most popular suggestion. Although a desire for relative privacy may contribute to this preference, some participants suggested highly visible public locations reflecting their own lifestyles (e.g. parks, outside shops) in order, perhaps, to maximise youth knowledge of where condoms can be accessed. However, there may be tensions inherent between the use of such 'youth lifestyle' public locations, the needs of other members of the community (e.g. parents of young children who may be offended) and the interests of CVM distributors (e.g. concerns about vandalism, theft). However, we do suggest that consideration of locations in which young people tend to spend their leisure time, and the differences amongst them in terms of age and gender, are likely to prove useful in attempts to increase accessibility of CVMs.

\section{Acknowledgements}

The authors would like to thank all the young people who participated in the interviews and questionnaire survey, and the youth workers who facilitated their access to many of them. They also thank Central Manchester Primary Health Care Trust and Galaxy 102FM for facilitating this study. Finally, a word of thanks goes to the anonymous reviewers who made useful comments on the first draft of this paper.

\section{Statements on funding and competing interests}

Funding. None identified.

Competing interests. None identified.

References

1 National Statistics. Conceptions in England and Wales, 2003. Health Stat $Q 2005 ; 26: 58-61$

2 Health Protection Agency (HPA). Renewing the Focus: HIV and Other Sexually Transmitted Infections in the UK in 2002 (Annual Report). London, UK, HPA, 2003; 44-45.

3 O'Sullivan I, Keyse L, Park N, Diaper A, Short S. Sexual behaviour and condom use (Chapter 5). Contraception and Sexual Health, 2004/05. London, UK: Office for National Statistics 2005; 28-34.

4 Lloyd T, Forrest S. Boys' and Young Men's Health: Literature and Practice Review. An Interim Report. London: Health Development Agency, 2001

5 Allen J, Bradley S. Family planning provision in the Trent health region: is it accessible to school aged teenagers? J Fam Plann Reprod Health Care 2001; 27: 13-15.

6 The Social Exclusion Unit. Teenage Pregnancy. Report No. Cmnd 4342. London, UK: The Stationery Office, 1999.

7 Smith A. Young people's contraception and sexual health: report of a local needs assessment in Staveley, North Derbyshire. J Fam Plann Reprod Health Care 2001; 27: 29-32.

8 Klein J, Rossbach C, Nijher H, Geist M, Wilson K, Cohn S, et al. Where do adolescents get their condoms? J Adolesc Health 2001; 29: 186-193.

9 Smart S. Addressing the needs of teenagers with a drop-in clinic. Nurs Stand 1996; 10: 43-45.

10 Department of Health. Sexual Health and HIV Strategy. Memorandum to the Select Committee on Health No. SH1. London, UK: The Stationery Office, 2002

11 Smith T. Influence of socio-economic factors on attaining targets for reducing teenage pregnancies. BMJ 1993; 306: 1232-1235.

12 Price N. The performance of social marketing in reaching the poor and vulnerable in AIDS control programmes. Health Policy Plan 2001; 16: 231-239.

13 Harden A, Ogden J. Sixteen to nineteen year olds' use of, and beliefs about, contraceptive services. Br J Fam Plann 1999; 24: 141-144.

14 Ogden J, Harden A. Beliefs about condoms in 12/13 and 16/17 year olds. AIDS Care 1995; 7: 205-210.

15 British Psychological Society. Ethical principles. Psychologist 1993; 6: $33-35$

16 British Psychological Society. Code of conduct. Psychologist 1995; 8: 452-453.

17 Boyatzis RE. Transforming Oualitative Information: Thematic Analysis and Code Development. Thousand Oaks, CA: Sage, 1998.

\section{Faces behind the Journal of Family Planning and Reproductive Health Care}

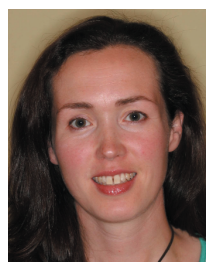

Brigid Molloy, BA, MB ChB, MRCGP, DRCOG (Associate Editor)

Brigid gained a degree in physiological sciences from Oxford University before graduating from Edinburgh University in 1994. She has been a general practitioner since 2000 and has been a partner at Pollokshaws Medical Centre in Glasgow for 5 years. Her main areas of interest include dermatology, family planning and gynaecology. 